\title{
Estimation of Influence Scope of Lateral Displacement of Soft Ground under Vacuum Pressure with PVD
}

\author{
Jingyun Liu, ${ }^{1}$ Hongtao $\mathrm{Fu}^{1}{ }^{1}$ Jun Wang $\mathbb{D}^{2},{ }^{2}$ Yuanqiang Cai, ${ }^{3}$ and Xiuqing $\mathrm{Hu}^{4}$ \\ ${ }^{1}$ College of Architecture and Civil Engineering, Wenzhou University, Wenzhou 325035, China \\ ${ }^{2}$ The Key Laboratory of Engineering and Technology for Soft Soil Foundation and Tideland Reclamation of Zhejiang Province, \\ Wenzhou University, Wenzhou 325035, China \\ ${ }^{3}$ Zhejiang University of Technology, Hangzhou 310014, China \\ ${ }^{4}$ Innovation Centre of Tideland Reclamation and Ecological Protection, Wenzhou University, Wenzhou 325035, China
}

Correspondence should be addressed to Jun Wang; sunnystar1980@163.com

Received 8 June 2018; Accepted 26 July 2018; Published 19 August 2018

Academic Editor: Yongfeng Deng

Copyright (C) 2018 Jingyun Liu et al. This is an open access article distributed under the Creative Commons Attribution License, which permits unrestricted use, distribution, and reproduction in any medium, provided the original work is properly cited.

\begin{abstract}
The application of vacuum pressure to a treated area not only induces vertical settlement and inward lateral displacement but also causes the formation of tension cracks near the ground surface. In general, the strain method is applied to calculate the lateral displacement at the boundary of a treated area; however, the influence scope of lateral displacement has not yet been presented. Based on the in situ data of soft clayey soil foundation treated by vacuum consolidation, lateral displacement was estimated in the influence scope in this study. To calculate the influence scope of lateral displacement induced by vacuum pressure, the ratio of the lateral displacement within the influence scope to the ground surface settlement under the centre of the treated area is defined as the maximum value of the lateral displacement (ELD) within the influence scope. This paper proposes a direct relationship between ELD and the distance from the treated area boundary $\left(L_{x}\right)$, considering the length of the prefabricated vertical drain. In addition, the FEA (finite-element analysis) is used to simulate the process of vacuum preloading to reinforce soft soil foundation. The influence scope simulated is almost close to the calculated value $L_{x}$. Accordingly, the safety distance between the boundary of the treated area and the surrounding building can be estimated when the soft soil foundation is consolidated by using a vacuum preloading method.
\end{abstract}

\section{Introduction}

The preloading of a soft clayey deposit through vacuum or embankment loading is commonly used as a soft ground improvement method. With several advantages over embankment loading, vacuum pressure applied to the processing of soft clay has a higher practicability, such as no fill material, shorter construction periods, and nonrequirement for heavy machinery. In addition, the vacuum preloading method does not add any chemical admixtures into the ground and is consequently an environmental-friendly ground improvement method $[1,2]$. However, owing to the principle effect of the vacuum preloading method, the treated area will not only induce vertical settlement and inward (toward the centre of the loading area) lateral displacement of the ground but also cause crack adjacent to the treated area. Especially, lateral displacement of soil at reclaimed coastal regions is more obvious because of the poor engineering properties of soft soil, as shown in Figure 1. In most preloading projects, the prediction of the consolidation settlement and lateral displacement of the ground is an essential design requirement. In particular, the prediction of ground lateral displacement induced by geotechnical engineering activities in an urban environment may sometimes be a crucial design consideration [3].

The current methods for calculating lateral displacement of soil consist of the strain method (the horizontal displacement at the boundary is calculated based on the strain of the soil in the treated area) [1] and the method of determining the ratio of the settlement and lateral displacement [4]. It is 


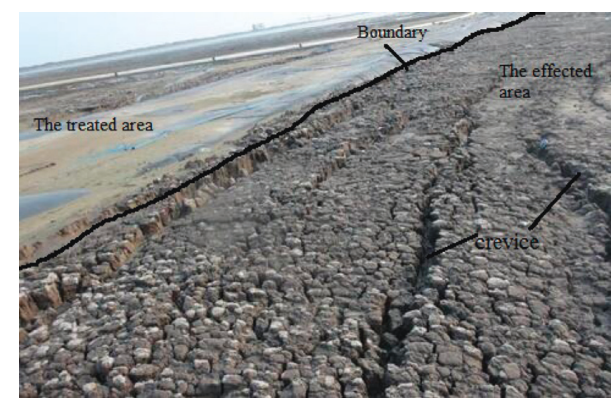

FIGURE 1: Deformation of the soil under vacuum consolidation.

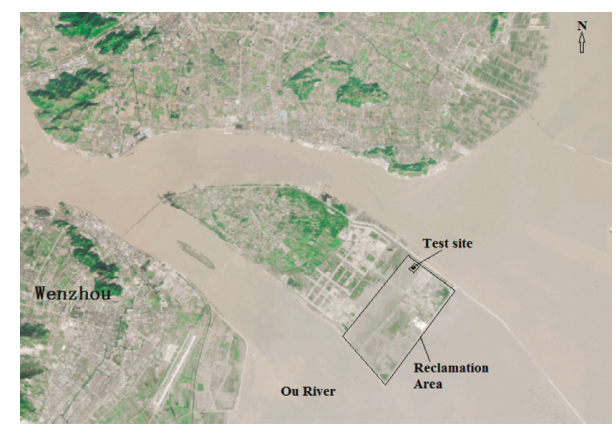

Figure 2: Location of the test.

noteworthy that the above methods are not used to solve the deformation of the soil influenced by the different lengths of a prefabricated vertical drain (PVD). Generally, the aforementioned methods can be used to calculate or analyse the lateral deformation of soil at the boundary of the treated area. As shown in Figure 1, in spite of the lateral displacement, soil crevices at the affected area are often induced by vacuum pressure. Till now, there is no practical, easy-to-use method to evaluate the effect of the scope induced by vacuum pressure to adjacent engineering structures.

In this study, according to a practical application of the vacuum preloading method to engineering practice, the strain method was generalised to calculate the lateral displacement of soil at the affected area. Furthermore, based on the observed results of the case history and the strain method, an empirical equation is proposed for calculating the influence scope of vacuum preloading method, considering the different lengths of PVD. Finally, the FEA was applied to compare the simulated range of influence with the calculated value $L_{x}$, to evaluate the feasibility of the empirical equation.

\section{Site and Soil Conditions}

Wenzhou Vocational Secondary School is located in the new district of Oujiang estuary, China. The site of this project is shown in Figure 2. The treated area covers approximately $157,820 \mathrm{~m}^{2}$.

The field is located in a reclamation area with different thicknesses of dredger fill at the ground surface. For the convenience of construction, the test site should be reinforced using the vacuum preloading method for preliminary shallow layer treatment. During this process, the strengthened depth is approximately $3-5 \mathrm{~m}$. Figure 3 shows the physical properties of the soil after shallow treatment, where the moisture content is still greater than $62 \%$, and the compression index is approximately 1.1. These characteristics cause the soil to produce a large postconstruction settlement $[5,6]$, which can only satisfy the bearing capacity for the smooth functioning of the light-weight machine but cannot meet the requirements of the foundation treatment. Thus, the test site should be further reinforced using a vacuum preloading method again because of the poor engineering properties of soft soil.

\section{In Situ Instrumentation}

According to different reinforcement requirements, two PVD lengths ( $0.1 \mathrm{~m}$ wide and $4.0 \mathrm{~mm}$ thick) were applied to this project. To prevent the pile of buildings from sloping into the construction, a $6 \mathrm{~m}$ PVD was adopted at Section 1. Similarly, a $15 \mathrm{~m}$ PVD was adopted at Section 2 to prevent the cracking of the pavement and playground in use. Both the PVDs were arranged in a winter sweet shape with a spacing of $0.8 \mathrm{~m}$.

Vacuum pressure was applied using the air-sealing sheet method [7], and the sheet used for this project was a $0.5 \mathrm{~mm}$ thick polyvinyl chloride (PVC) membrane. Before placing the sealing membrane, three layers of geotextiles were laid down, and a sealing membrane was placed around in the sealing groove. In addition, the groundwater level at the site was approximately $0.48 \mathrm{~m}$ from the ground surface. To avoid air leakage through the top unsaturated zone, the edges of the sealing sheet were embedded in a $1.5 \mathrm{~m}$ deep trench.

After installing the PVDs, 13 surface settlement plates, 53 multilevel settlement gauges, and 11 inclinometers were installed to monitor the performance of the treated ground. Figures 4(a) and 4(b) present the general plan views of the test sites, and Table 1 tabulates the installed depths of the layered settlement gauges.

The measured vacuum pressure applied under the airsealing sheet was over $80 \mathrm{kPa}$. At the time of stopping the vacuum pump, the measured ground surface average settlement from Sections 1 and 2 was approximately 908 and $1197 \mathrm{~mm}$, respectively. The curve of the settlement over time in each treated area is shown in Figures 5(a) and 5(b).

\section{Lateral Displacement}

4.1. At the Boundary of Treated Area. For the soft soil foundation, the soil can be considered in the $K_{0}$ consolidation state. If only the vacuum pressure is larger than the lateral stress required for a no horizontal strain condition, an inward lateral displacement is observed. Based on a series of test results, Chai et al. [1] reported an approximate method for calculating the ground lateral displacement induced by vacuum pressure. Their method was used in the current study to calculate the lateral displacement of soil at boundary of the treated area. The dimensions of Sections 1 and 2 were $230 \mathrm{~m} \times 101 \mathrm{~m}$ and $185 \mathrm{~m} \times 140 \mathrm{~m}$ (length $\times$ width), respectively. Table 2 lists the information needed to calculate the lateral displacement induced by vacuum consolidation by using the approximate method. 


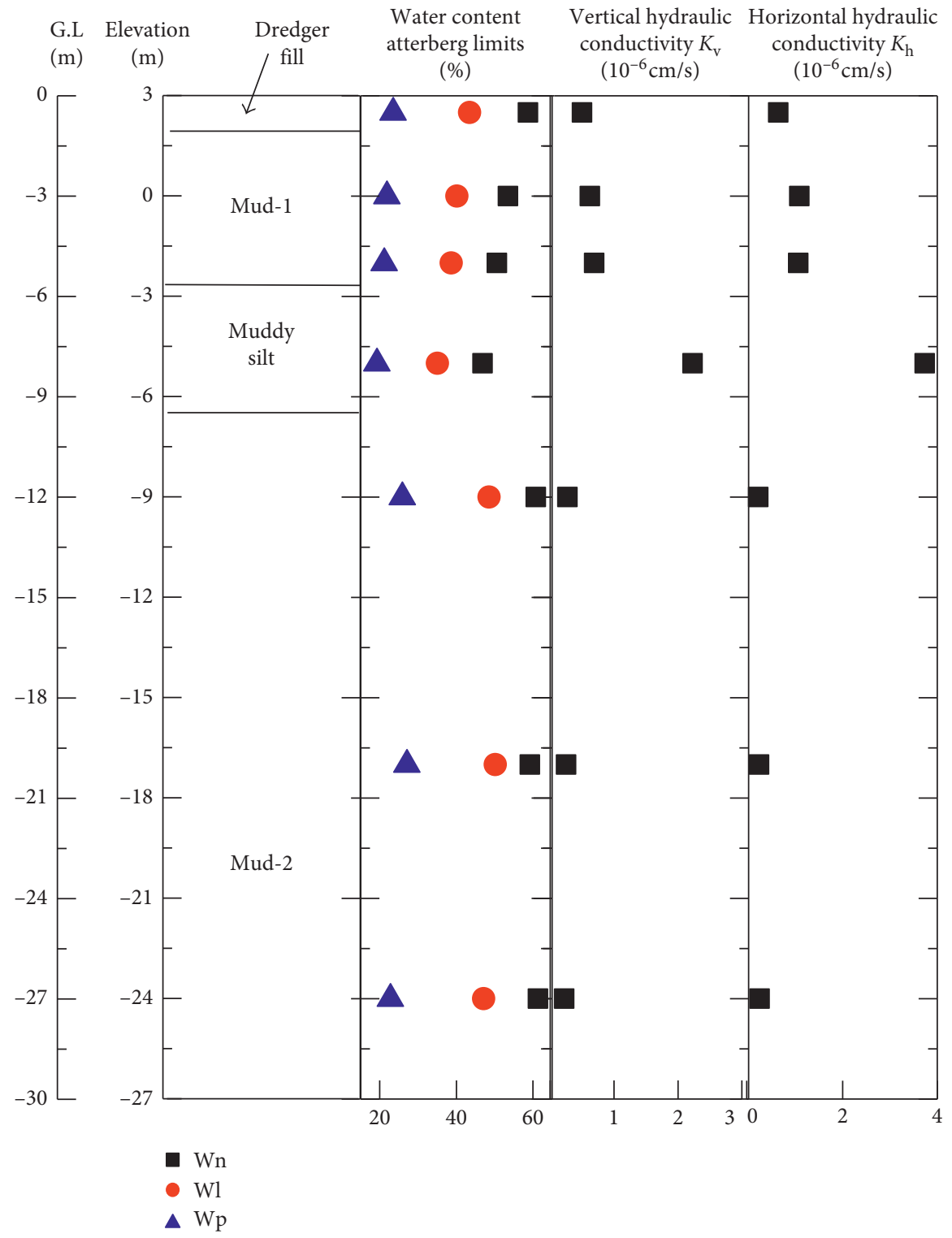

FIGURE 3: Soil profile and some physical properties at the test site.

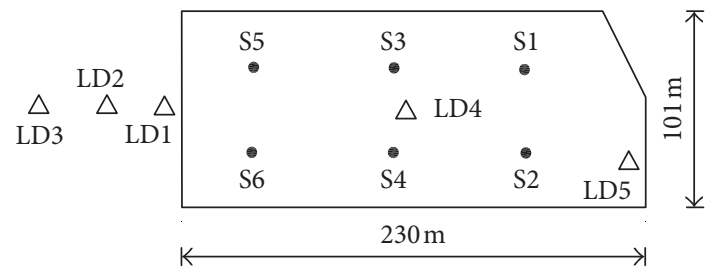

- Layered settlement gauge (S)

$\triangle$ Inclinometer casing (LD)

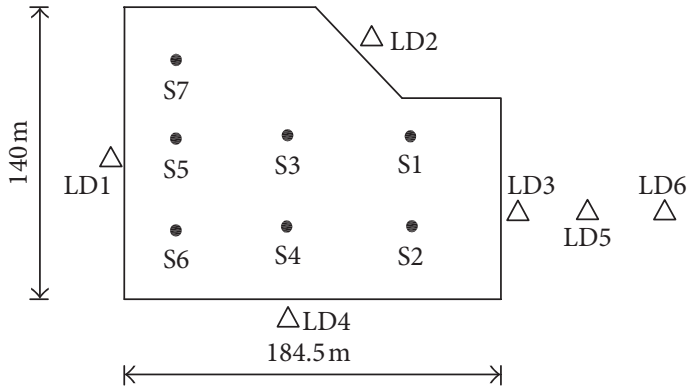

- Layered settlement gauge (S)

$\triangle$ Inclinometer casing (LD)

(a)

(b)

Figure 4: Plan layout of instrumentation points. (a) Section 1 and (b) Section 2. 
TABLE 1: Installed depth of layered settlement gauges.

\begin{tabular}{lrr}
\hline & Monitoring points & Installed depth (m) \\
\hline Section 1 & S1, S2, S3, S4, S5, S6 & $1.5,4.5,7.5$ \\
Section 2 & S1, S2, S3, S4, S5, S6, S7 & $1.5,4.5,7.5,10.5,15.0$ \\
\hline
\end{tabular}

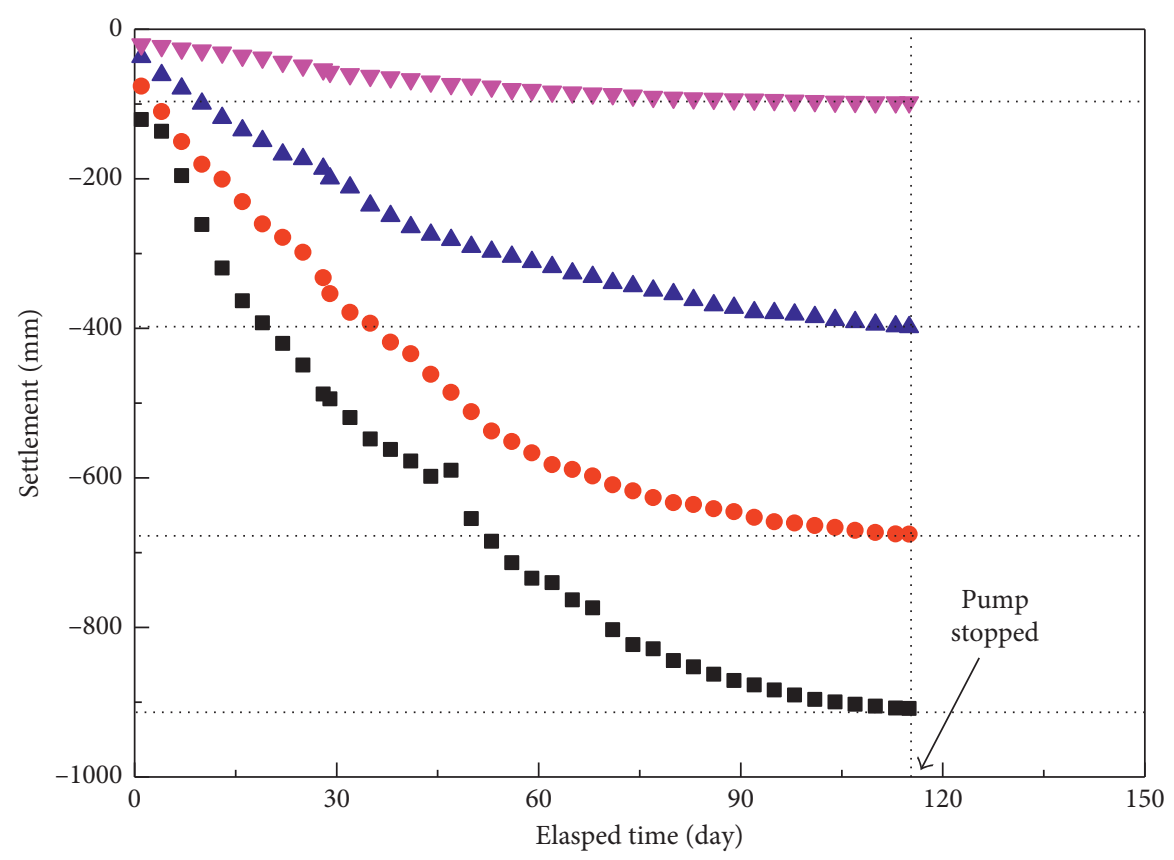

- Ground surface

- S1 (GL-1.5 m)

$\Delta \quad \mathrm{S} 2(\mathrm{GL}-4.5 \mathrm{~m})$

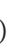

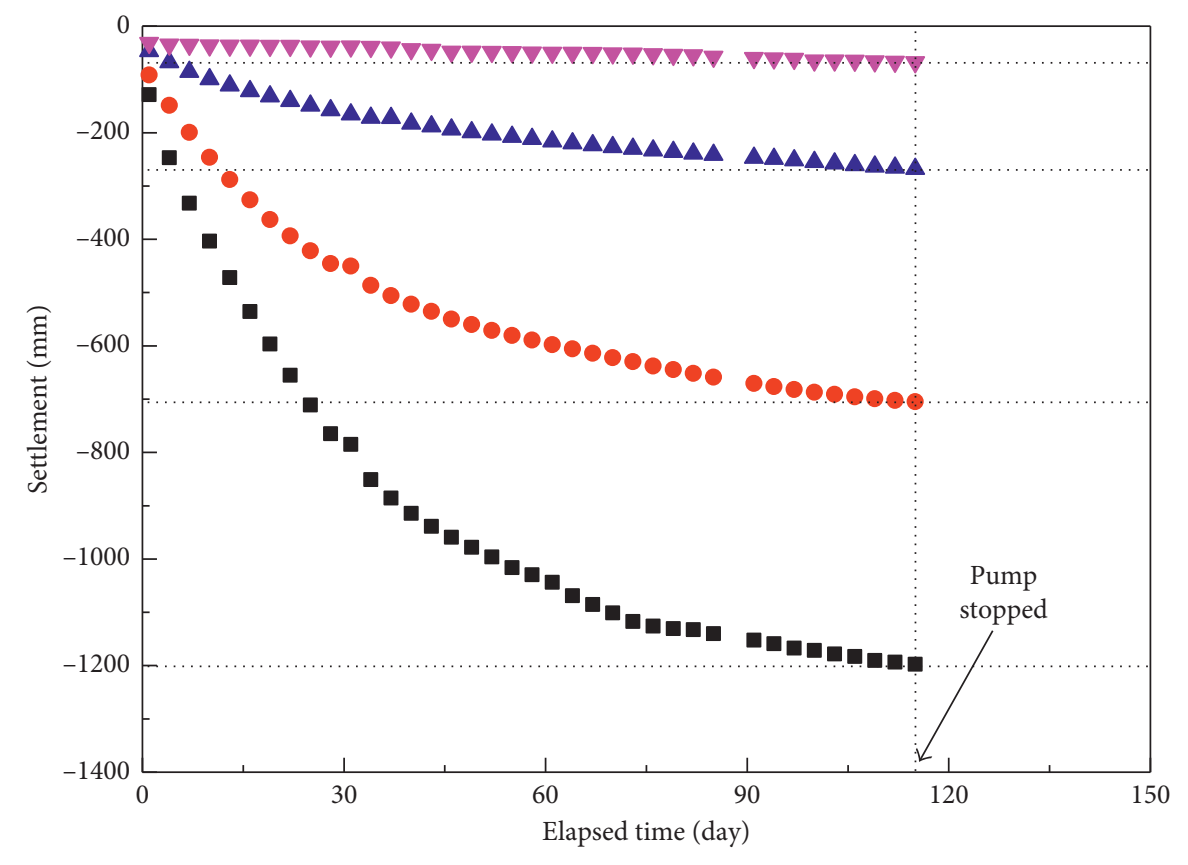

- Ground surface

- S1 (GL-1.5m)

$$
\begin{array}{ll}
\boldsymbol{\nabla} & \mathrm{S} 2(\mathrm{GL}-4.5 \mathrm{~m}) \\
\nabla & \mathrm{S} 3(\mathrm{GL}-7.5 \mathrm{~m})
\end{array}
$$

(b)

Figure 5: Settlement versus elapsed time curve. (a) Section 1 and (b) Section 2. 
Table 2: Parameters for the soil at Wenzhou Vocational Secondary School Foundation.

\begin{tabular}{lcccccccc}
\hline & $K_{0}$ & $K_{\mathrm{a}}$ & $\mathrm{c}^{\prime}(\mathrm{kPa})$ & $\gamma_{\mathrm{t}}\left(\mathrm{kN} / \mathrm{m}^{3}\right)$ & $\lambda$ & $e$ & $E_{\mathrm{s}}(\mathrm{MPa})$ & $\phi^{\prime}\left({ }^{\circ}\right)$ \\
\hline Dredger fill & 0.8246 & 0.7016 & 8.3 & 16 & -0.1717 & 1.639 & 1.98 & 10.1 \\
Mud 1 & 0.8958 & 0.6747 & 7.9 & 16.5 & -0.1659 & 1.516 & 1.34 \\
Muddy silt clay & 0.6596 & 0.4921 & 7.4 & 17 & -0.2645 & 1.267 & 2.31 \\
Mud 2 & 0.847 & 0.7346 & 10.3 & 15.8 & -0.1063 & 1.718 & 1.67 \\
Silty clay & 0.7802 & 0.6396 & 14.5 & 16.8 & -0.2362 & 1.312 & 2.48 & 24.5 \\
\hline
\end{tabular}

Note. $K_{\mathrm{a}}$ is the active earth pressure coefficient; $K_{\mathrm{a}}=\tan ^{2}\left(45-\left(\phi^{\prime} / 2\right)\right)$.

The method proposed by Chai et al. [1] for calculating lateral displacement of the soil at the treated area boundary as a result of the vacuum-drain consolidation can be summarized as follows:

(1) horizontal earth pressure coefficient calculation:

$$
K_{\mathrm{a} 0}=\beta K_{\mathrm{a}}+(1-\beta) K_{0},
$$

where $K_{\mathrm{a}}$ is the active earth pressure coefficient, $K_{0}$ is the at-rest earth pressure, and $\beta$ is an empirical factor. It is suggested that $\beta$ should normally be assigned a value in the range from 0.67 to 1 .

(2) The maximum depth $\left(z_{1}\right)$ calculation of soil with lateral displacement is as follows:

$$
\begin{aligned}
& Z_{\mathrm{c}}=\frac{2 c^{\prime}}{\gamma_{\mathrm{t}} \sqrt{K_{\mathrm{a}}}}, \text { for } z_{\mathrm{c}}<z_{\mathrm{w}} \text {, } \\
& Z_{\mathrm{c}}=\frac{1}{\gamma_{\mathrm{t}}-\gamma_{\mathrm{w}}}\left(\frac{2 c^{\prime}}{\sqrt{K_{\mathrm{a}}}}-\gamma_{\mathrm{w}} z_{\mathrm{w}}\right), \quad \text { for } z_{\mathrm{c}}>z_{\mathrm{w}} \\
& \sigma_{\mathrm{av}}^{\prime}=<z^{\prime} \gamma^{\prime} K_{\mathrm{a} 0} \geq \begin{cases}0, & \text { for } z<z_{\mathrm{c}}, \\
K_{a 0} z^{\prime} \gamma^{\prime}, & \text { for } \mathrm{z}_{\mathrm{l}}>\mathrm{z}>\mathrm{z}_{\mathrm{c}},\end{cases} \\
& \Delta \sigma_{\mathrm{vac}}=\frac{K_{0} \cdot \sigma_{\mathrm{v} 0}^{\prime}-\sigma_{\mathrm{av}}^{\prime}}{1-K_{0}},
\end{aligned}
$$

where $\gamma_{\mathrm{t}}$ is total unit weight of soil, $\gamma_{\mathrm{w}}$ is the unit weight of pore water, $c^{\prime}$ is the effective stress cohesion, $z_{\mathrm{c}}$ is the depth of cracking, $z_{\mathrm{w}}$ is the groundwater level, and the depth below which no lateral displacement occurs in the soil is given as $z_{1}=z_{\mathrm{c}}+z^{\prime}$.

(3) The variation of the model parameter $(\alpha)$ with depth is given as

$$
\alpha=\alpha_{\min }+\frac{1-\alpha_{\min }}{\Delta \sigma_{\mathrm{vac}}}\left(\frac{K_{0} \sigma_{\mathrm{v} 0}^{\prime}-\sigma_{\mathrm{av}}^{\prime}}{1-K_{0}}\right), \quad \text { for } z_{\mathrm{c}} \geq z \geq z_{1} .
$$

(4) The calculations for volumetric and horizontal strains are given as

$$
\begin{aligned}
\varepsilon_{\mathrm{vol}} & =\frac{\lambda}{1+e} \ln \left(1+\frac{\Delta \sigma_{\mathrm{vac}}}{\sigma_{\mathrm{v} 0}^{\prime}}\right), \\
\varepsilon_{\mathrm{h}} & =\frac{1}{2}(1-\alpha) \frac{\lambda}{1+e} \ln \left(1+\frac{\Delta \sigma_{\mathrm{vac}}}{\sigma_{\mathrm{v} 0}^{\prime}}\right),
\end{aligned}
$$

where $\lambda$ is the virgin compression index in an $e-\ln p^{\prime}$ plot, $e$ is the voids ratio, $\Delta \sigma_{\text {vac }}$ is the incremental vacuum pressure of the treated area, $\sigma_{\mathrm{a} 0}^{\prime}$ is the in situ vertical effective stress in the treated area, and $\sigma_{\mathrm{av}}^{\prime}$ is the horizontal effective stress. Parameters $\varepsilon_{\mathrm{h}}$ and $\varepsilon_{\mathrm{vol}}$ are the horizontal and volumetric strains under vacuum consolidation, respectively.

(5) Lateral displacement of the soil at the treated area boundary is given as

$$
\delta_{\mathrm{h}}=\varepsilon_{\mathrm{h}} B,
$$

where $B$ is the half width of the treated area.

It is suggested that for triaxial stress conditions, the model parameter $\alpha_{\min }=0.8$, where $\alpha$ has the minimum value $\left(\alpha_{\min }\right)$ at the ground surface. Moreover, the parameter reaches a unit value when $z>z_{1}$. In this case, the initial effective stress applied to the field is zero or at least close to zero. The lateral displacements of the boundaries of two treatment sections are shown in Figures 6(a) and 6(b).

According to the calculation results, the value of $\beta$ mainly influences the lateral displacement at deeper locations and the calculated depth at which the lateral displacement becomes insignificant. The smaller the $\beta$ value is, the larger the calculated lateral displacement is and the larger the $z_{1}$ value (below which no lateral displacement occurs in the soil) is. In Section 1 , when $\beta=0.67, z_{1} \cong 21 \mathrm{~m} ; \beta=0.84$, $z_{1} \cong 16.5 \mathrm{~m}$; and $\beta=1, \mathrm{z}_{1} \cong 14 \mathrm{~m}$. In contrast, in Section 2 , when $\beta=0.67, z_{1} \cong 26 \mathrm{~m} ; \beta=0.84, z_{1} \cong 20 \mathrm{~m}$; and $\beta=1$, $z_{1} \cong 17 \mathrm{~m}$. The comparison of the calculation results shows that the $z_{1}$ value is not related to the depth of the PVD. In addition, the overall value of $\beta=1.0$ seems to provide a better simulation of the in situ data. Of course, $\beta=1.0$ corresponds to the active earth pressure state and will obviously underestimate the earth pressure for soil at depths near $z_{1}$. The figure shows that the longer the length of the PVD is, the greater the depth of the reinforcement is and the greater the maximum horizontal displacement is.

4.2. In the Affected Area. Although the mechanism of vacuum preloading method is researched relatively perfectly, the influence of vacuum pressure on the consolidation and deformation of soil adjacent to the treated area is not very clear. According to the actual situation of engineering applications, in this study, the formula used to calculate the lateral deformation of the soil of the treated area boundary is generalised to calculate lateral deformation of the affected area. 


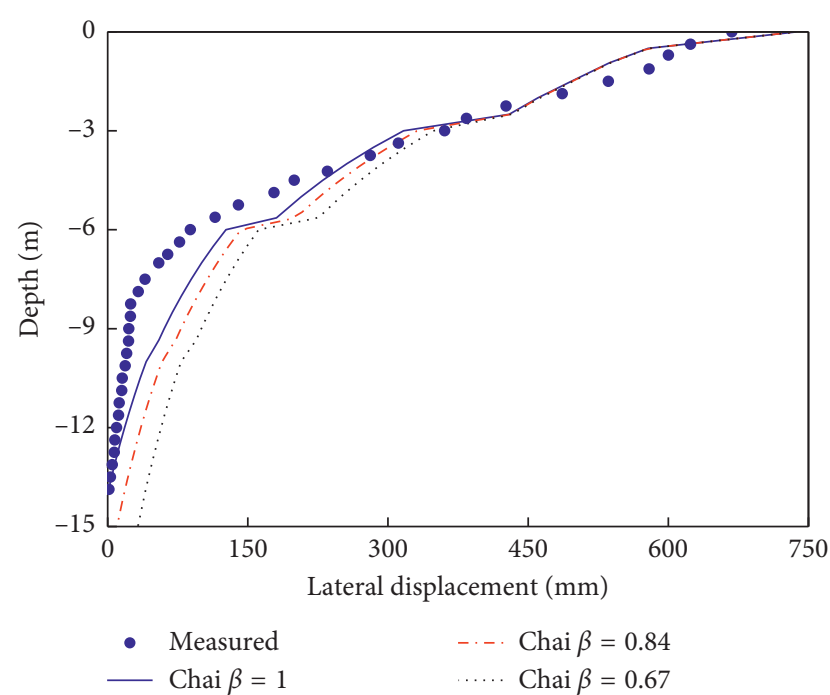

(a)

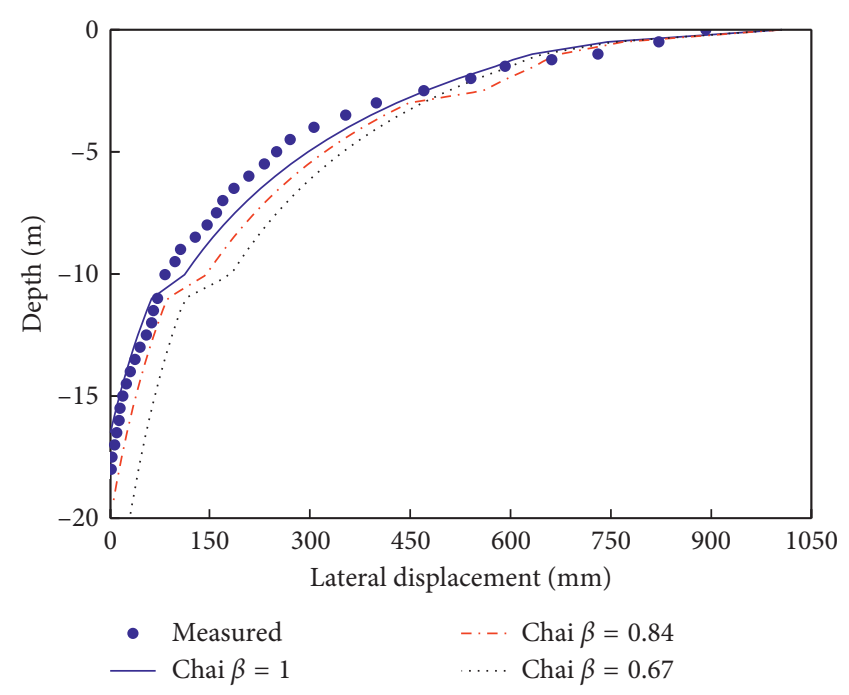

(b)

Figure 6: Lateral displacement of soil at treated area. (a) Section 1 and (b) Section 2.

The following changes have been adapted in the process of calculating the lateral displacement for the expansion of the strain method:

(1) According to a series of laboratory tests, Robinson [8] proposed that lateral stresses should be considered when estimating the vertical strains of the soil in the affected area. The magnitude of vertical and lateral strains also depends on the magnitude of horizontal stress. When the horizontal stress from the affected area is equivalent to the active pressure, a more vertical settlement is observed compared to when the horizontal stress is equivalent to the earth pressure at rest. Similarly, the lateral strain is greater when the horizontal stress from the affected area is at rest. Assuming that the volumetric strain varies with the magnitude of the vacuum pressure in the affected area, the effective volumetric strain of the soil in the affected area can be calculated according to (6a) as follows:

$$
\varepsilon_{\mathrm{vol}-e}=\eta \times \varepsilon_{\mathrm{vol}}
$$

where $\eta$ is the attenuation coefficient of the volumetric strain.

Kondner [9] proposed a hyperbolic function to describe the stress-strain relationship of clay soil consolidation drainage tests.

$$
\frac{\varepsilon_{\mathrm{vol}-e}}{\sigma_{1}-\sigma_{3}}=a+b \varepsilon_{\mathrm{vol}-e}
$$

where $\sigma_{1}$ and $\sigma_{3}$ are the maximum and minimum principal stresses, respectively. According to the stress-strain normalization characteristics of cohesive soil [10], $a$ and $b$ can be calculated from the stress-strain values of the treated area. When $K_{0}=0.65, a=0.0002$ and $b=0.0342$, and when
$K_{0}=0.89, a=0.0007$ and $b=0.1089$. According to (9) and (10), the calculated value of $\eta$ is given in Table 3.

(2) Under plane strain conditions, the lateral strain factor (LF), which is the ratio of lateral strain $\left(\varepsilon_{\mathrm{h}-e}\right)$ to volumetric strain $\left(\varepsilon_{\mathrm{vol}-e}\right)$, can be determined by the method of Poulos and Davis [11] as

$$
\mathrm{LF}=\frac{\varepsilon_{\mathrm{h}-e}}{\varepsilon_{\mathrm{vol}-e}}=\frac{\chi(1-\nu)-v}{(1+\chi)(1-2 v)},
$$

where $\chi=\Delta \sigma_{\mathrm{vac}, \mathrm{h}} /\left(\Delta \sigma_{\mathrm{vac}, \mathrm{v}}+\sigma_{\mathrm{vo}}^{\prime}\right), \sigma_{\mathrm{v} 0}^{\prime}$ is the in situ vertical effective stress in the affected area, and $v$ is Poisson's ratio. Under $k_{0}$ condition $\left(\chi=k_{0}\right)$, there is no lateral deformation, such that

$$
v=\frac{K_{0}}{1+K_{0}} .
$$

(3) The lateral displacement at distance $L_{x}$ from the boundary of the affected area can be calculated by

$$
\delta_{\mathrm{h}-e}=\varepsilon_{\mathrm{h}-e} \times L_{x},
$$

where $\varepsilon_{\mathrm{h}-e}$ is the horizontal strain of the soil in the affected area and $L_{x}$ is the distance from the treated area boundary $(\mathrm{m})$.

Figure 7 plots the variations in the LF, where the $\mathrm{LF}=0$ when $\chi=K_{0}$. A stress ratio $(k)[1]$ was defined as

$$
k=\frac{\Delta \sigma_{\mathrm{vac}}}{\Delta \sigma_{\mathrm{vac}}+\sigma_{\mathrm{vo}}^{\prime}} .
$$

They postulated that if $k \leq K_{0}$, there will be no lateral displacement and vice versa. The lateral deformations of the different distances of the treated area boundary are shown in Figures 8-11. Despite the affected area being 
TABLE 3: Calculation results of the $\eta$ value.

\begin{tabular}{lcccccc}
\hline & \multicolumn{2}{c}{ Section 1 } & \multicolumn{2}{c}{ Section 2 } \\
\multicolumn{2}{c}{$K_{0}=0.65$} & \multicolumn{2}{c}{$K_{0}=0.89$} & $K_{0}=0.65$ & $K_{0}=0.89$ \\
\hline$L_{x}=10$ & $L_{x}=20$ & $L_{x}=10$ & $L_{x}=20$ & $L_{x}=10$ & $L_{x}=20$ & $L_{x}=10$ \\
0.1160 & 0.0502 & 0.1274 & 0.0552 & 0.1151 & 0.0500 & 0.1268 \\
\hline
\end{tabular}

Note. $K_{0}$ is the at-rest earth pressure; $L_{x}$ is the distance from the treated area boundary $(\mathrm{m})$.

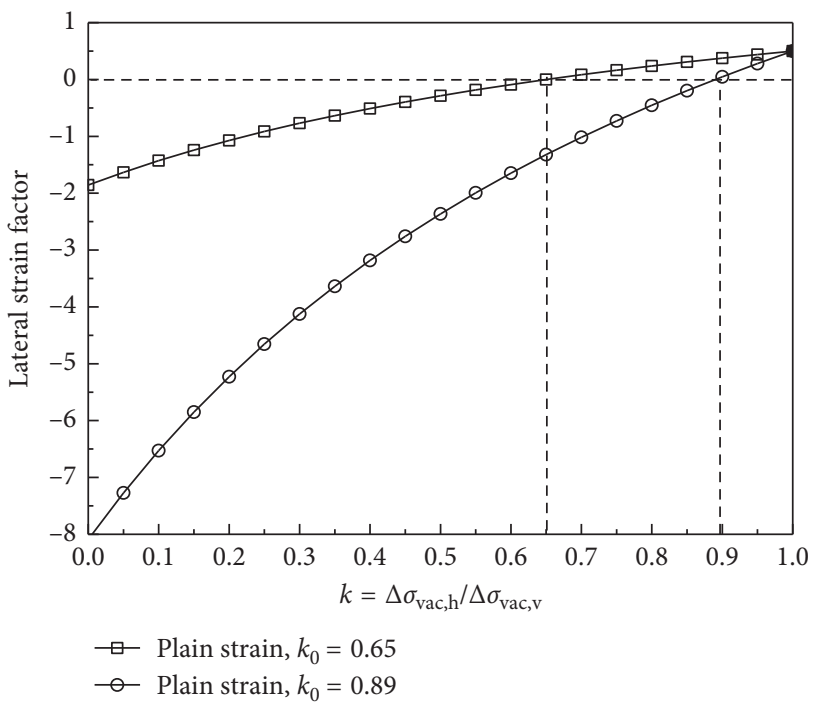

FIGURE 7: Lateral strain factor variations.

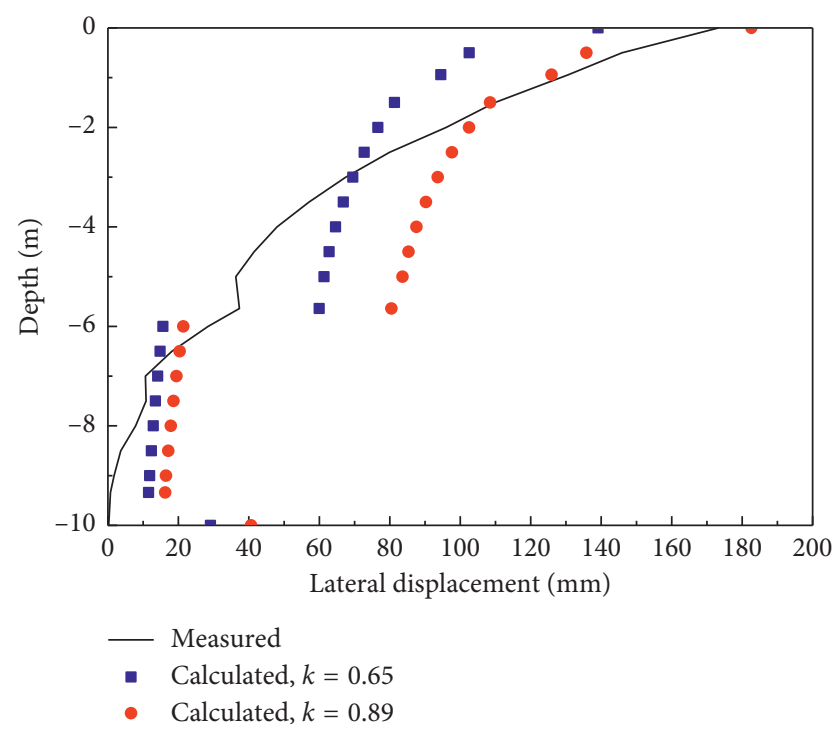

FIGURE 8: Lateral displacement at a distance of $10 \mathrm{~m}$ from Section 1 boundary.

without air-sealing sheet, the surface or subsurface soil layer acts as an equivalent air-sealing sheet for sealing the upper soil layer. This method was proposed by Chai et al. [12].

As the vacuum in the affected area is less than that in the treated area, the farther it is away from the boundary of the treated area, the smaller the degree of the vacuum

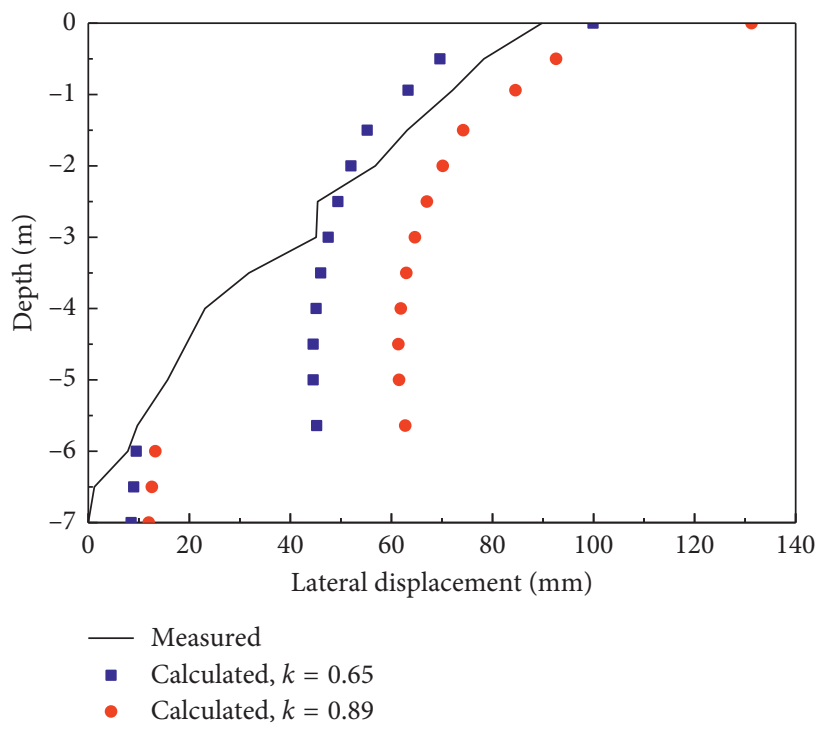

FIGURE 9: Lateral displacement at a distance of $20 \mathrm{~m}$ from Section 1 boundary.

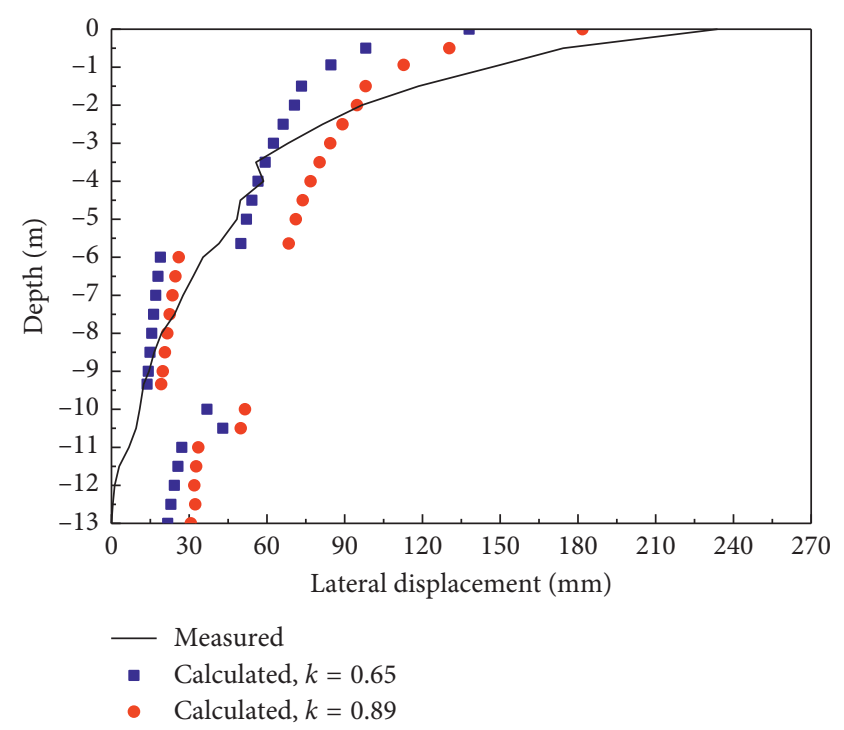

FIGURE 10: Lateral displacement at a distance of $10 \mathrm{~m}$ from Section 2 boundary.

is. Assuming that the attenuation rate of vacuum pressure is $2 \mathrm{kPa} / \mathrm{m}$ in the horizontal direction, the vacuum pressures at 10 and $20 \mathrm{~m}$ distance from the treated area boundary are 60 and $40 \mathrm{kPa}$, respectively; it was observed that it mainly depended on the vacuum pressure at the 


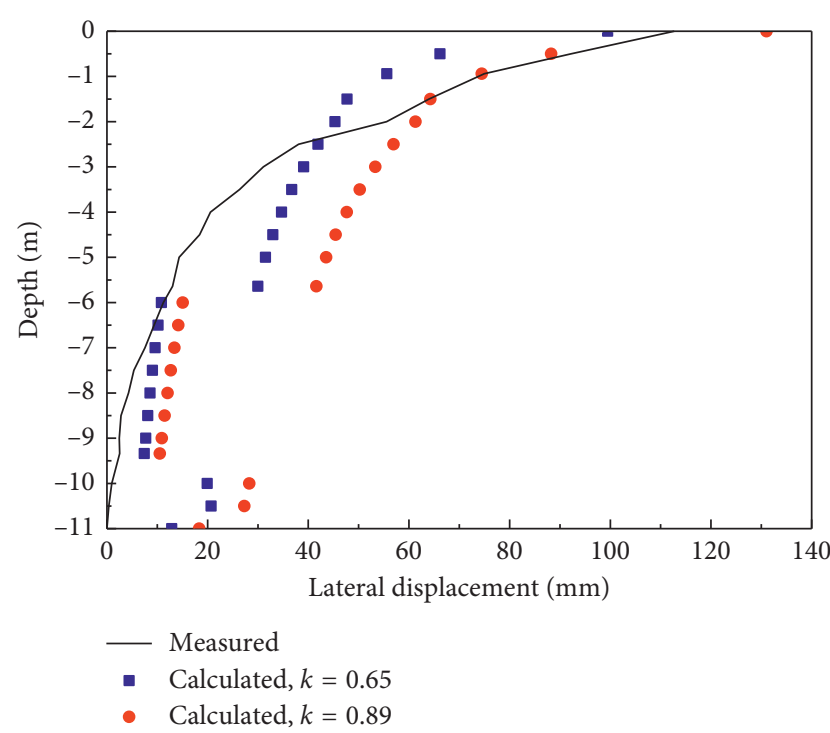

Figure 11: Lateral displacement at a distance of $20 \mathrm{~m}$ from Section 2 boundary.

ground surface. These assumptions are attributed to the following factors:

(a) Owing to the surface or subsurface soil layer being the sealing layer, the soil of the affected area could be maintained under the influence of vacuum pressure.

(b) In the range of natural sludge, the attenuation rate of vacuum pressure in horizontal direction is $6 \mathrm{kPa} / \mathrm{m}$ in the vertical direction [13].

(c) The attenuation of the vacuum is responsible for the permeability coefficient of the soil; the greater the permeability coefficient is, the slower the attenuation rate is [14]. In this case, the horizontal permeability coefficient of the soil is approximately three times of the vertical permeability coefficient.

At the affected area, the vacuum pressure can be considered to vary linearly from the ground surface to $z_{1}$ (below which no lateral displacement occurs in the soil) [1]. In the affected area, the coefficients of lateral earth pressure were assumed to vary linearly from $k_{0}$ at the bottom of the drain to $k_{\mathrm{a}}$ at the surface [8]. The calculated inward lateral earth pressures with $k=0.65$ and 0.89 under plane strain conditions are plotted in Figures 8-11. The figures show that at shallow depths, $\chi=0.89$ can predict the lateral displacement very well, whereas the measured values approach the predicted values when $k=0.65$ (at-rest condition). It is noted that the sudden change of $k$ at the boundary of the soil layer was attributed to a change in the parameters of soil between each layer.

\section{Scope of Influence under Vacuum Pressure}

Under vacuum consolidation, the settlement and lateral displacement induced by the vacuum pressure were determined. The effective stress increased in the treated area, which will cause soil reinforcement outside of the treated area in some way and induced the lateral displacement. Through research, many domestic scholars believe that the range of influence under the vacuum pressure is approximately 22-42 $\mathrm{m}$ [15]. Although the vacuum preloading method has been widely used, at present there has been no practical, easy-to-use method for predicting the scope. Based on the observed results of case histories, an empirical equation was proposed in the present study for estimating the maximum value of the scope.

The maximum value of the effected lateral displacement (ELD), which is a dimensionless parameter, can be expressed as

$$
\mathrm{ELD}=\frac{\delta_{\mathrm{h}-e}}{s}
$$

where $S$ is the ground surface settlement under the centre of the treated area. The values of $S$ and $\delta_{\mathrm{h}-\mathrm{e}}$ at the end of vacuum consolidation are desirable for substitution in this equation.

As the shallow soil is subjected to vacuum pressure to produce tension cracks, the soil can be considered to be close to the isotropic consolidation. However, no tensile cracks were observed in the lower soil, and the soil is considered to be close to a one-dimensional consolidation. According to the settlement calculation formula proposed by Liu et al. [16], $S$ can be calculated as

$S=\sum_{1}^{n} \alpha_{i} \cdot \frac{\Delta \sigma_{\mathrm{vac}}-20 \% \times \Delta \sigma_{\mathrm{vac}} \cdot\left(h_{i} / \mathrm{Z}_{\mathrm{i}}\right)}{E_{i}} \cdot h_{i}, \quad$ for $0<h_{i} \leq Z_{\mathrm{l}}$,

where $E_{i}$ is the compression modulus of each soil layer and $h_{i}$ is the thickness of each soil layer. The calculated settlement values in Sections 1 and 2 are 821.4 and $1105.3 \mathrm{~mm}$, respectively. It is obvious that the calculated value is less than that obtained in the in situ observations. The defined errors for Sections 1 and 2 are 9.5\% and 7.7\%, respectively, and meet the engineering requirements.

According to the monitoring data analysis, the relationship between ELD and $L_{x}$ (the distance from the treated area boundary) can be expressed as follows:

$$
\mathrm{ELD}=a \ln \left(L_{x}\right)+b,
$$

where $L_{x}$ is the value of distance from the treated area boundary $(\mathrm{m})$. When the length of PVD is $6 \mathrm{~m}, a=-0.185$ and $b=0.643$. When the length of PVD is $15 \mathrm{~m}, a=-0.185$ and $b=0.6541$. For a $6 \mathrm{~m}$ PVD length, when $\delta_{\mathrm{h}-\mathrm{e}}=0$ and $30 \mathrm{~mm}$ as the boundary, $L_{x}=32.32$ and $26.53 \mathrm{~m}$, respectively. For a $15 \mathrm{~m}$ PVD length, when $\delta_{\mathrm{h}-\mathrm{e}}=0$ and $30 \mathrm{~mm}$ as the boundary, $L_{x}=34.32$ and $29.63 \mathrm{~m}$, respectively. The relationship between the values of $L_{x}$ and ELD analysed from the measured results of the field cases and calculation is plotted in Figures 12(a) and 12(b).

\section{Numerical Simulation}

The present authors considered a PVD-induced horizontal radial consolidation and simulated through FEA (finite-element analysis) and analysed. The FEA is performed by the use of Plaxis 2D (version 2017.01). And the soft soil model (SSM) was 


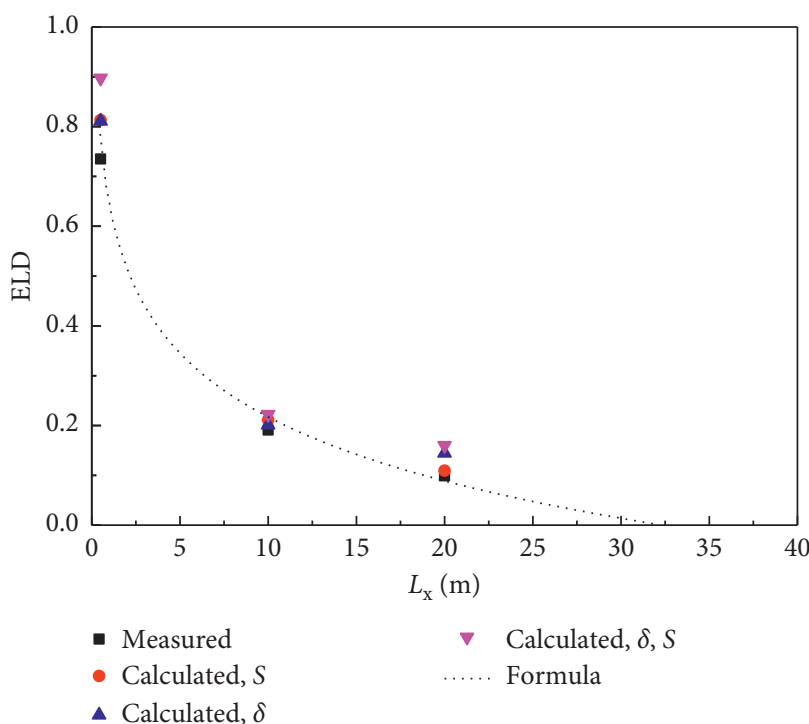

(a)

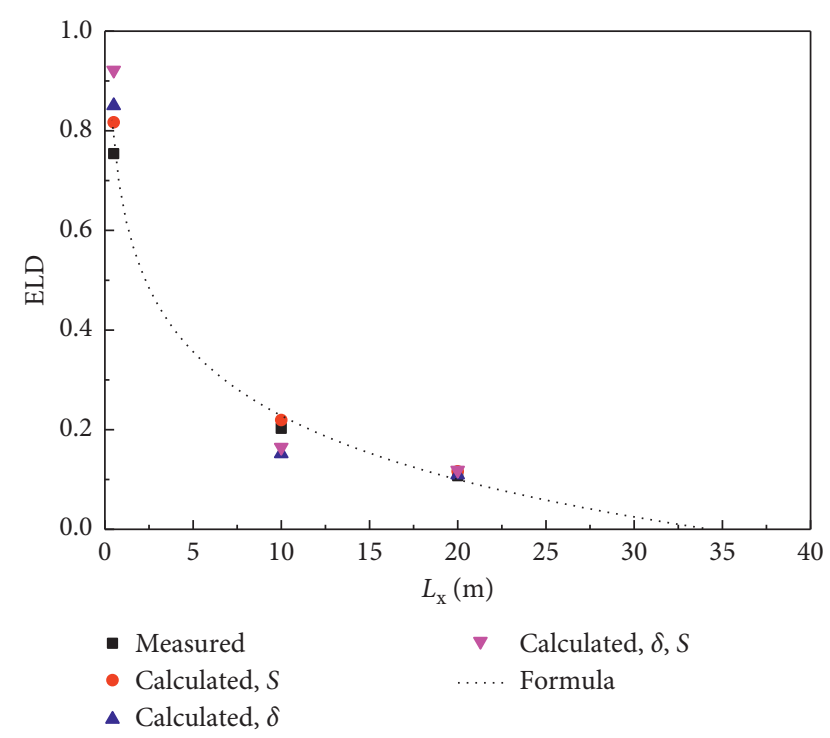

(b)

Figure 12: Relationship between the values of $L_{x}$ and ELD. (a) Section 1 and (b) Section 2.

adopted. The model used in the FEA is shown in Figure 13. Meshing is divided finely. In Section 1 case, there are 3882 elements and 31789 nodes, and there are 5326 elements and 43241 nodes in Section 2 case. $X_{\min }=0 \mathrm{~m}, X_{\max }=345 \mathrm{~m}$ and $Y_{\min }=-40 \mathrm{~m}, \quad Y_{\max }=0 \mathrm{~m}$ for case 1 , and $X_{\min }=0 \mathrm{~m}$, $X_{\max }=276 \mathrm{~m}$ and $Y_{\min }=-40 \mathrm{~m}, Y_{\max }=0 \mathrm{~m}$ for case 2 .

The values of the model parameters are listed in Table 2 and Figure 3. Two ideal cases without the effect of smear and well resistance were considered for the PVD-induced consolidation.

It was assumed that the model ground was weightless with an initial vertical effective stress of $K_{0}$ consolidation condition, and an incremental load of vacuum pressure was then applied at the top boundary. The Taylor [17] equation was used to consider the permeability variation with the void ratio reduction:

$$
k=k_{0} \times 10^{-\left(\left(e_{0}-e\right) / c_{\mathrm{k}}\right)},
$$

where $e_{0}$ and $e$ are the initial and current void ratios, $k_{0}$ and $k$ are the permeability corresponding to void ratios $e_{0}$ and $e$, respectively, and $c_{k}$ is a constant. The coefficient of consolidation, $c$, can be calculated as

$$
c=\frac{(1+e) k \cdot p^{\prime}}{\lambda \cdot \gamma_{\mathrm{w}}}
$$

where $p^{\prime}$ is the consolidation stress, $\lambda$ is the slope of the virgin compression curve in the $e-\ln p^{\prime}$ plot, and $\gamma_{\mathrm{w}}$ is the unit weight of water. The duration of vacuum consolidation maintained for 113 days in Section 1 and 103 days in Section 2. After the vacuum was completed, the horizontal displacement of the soil in each section case was shown in Figures 14 and 15.

It can be seen from Figures 14 and 15 in the process of the vacuuming, the soft soil in the affected area continuously moves towards the centre of the treated area under the influence of

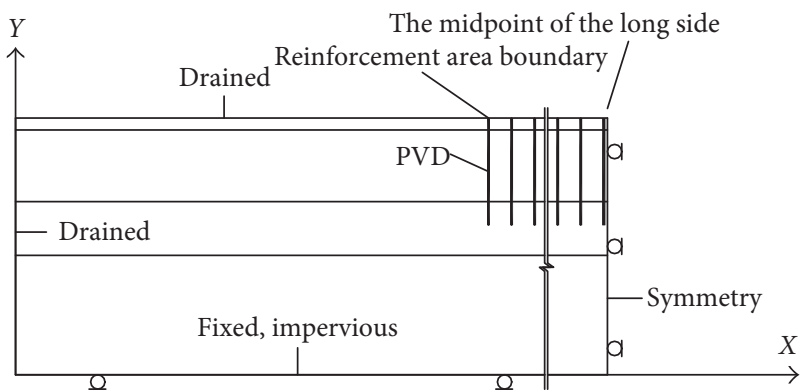

FIgURE 13: Model for FEA.

vacuum, and the maximum lateral displacement occurs at the boundary of the treated area. The result of this deformation has agreement with in situ data measured. The surface lateral displacement development of the two affected areas is summarized in Figure 16. The surface lateral displacement within the range of $0-15 \mathrm{~m}$ outside the treated area greatly developed, while the lateral displacement in the $15-25 \mathrm{~m}$ range developed slowly, specially, the surface lateral displacement is smaller at the $25 \mathrm{~m}$ away from the treated area. Meanwhile, it can be considered that $L_{x \max }$ is equal to $34 \mathrm{~m}$ in Section 1 and $L_{x \max }$ is equal to $37 \mathrm{~m}$ in Section 2. This is basically close to the result of calculation. According to the calculation results of (14)-(16), $L_{x \max }$ of Sections 1 and 2 are equal to 32.32 and 34.32, respectively.

To confirm the safe distance between the boundary of treated area and structure, a series of factors must be considered carefully, which consist of the ability to resist structural deformation, type of structural infrastructure, and soil properties inside and outside the treated area. According to the calculation results from (14) to (16) and simulation, it is feasible for engineering practice that the safe distances away from the treated area can be determined to 32.32 and $34.32 \mathrm{~m}$. 


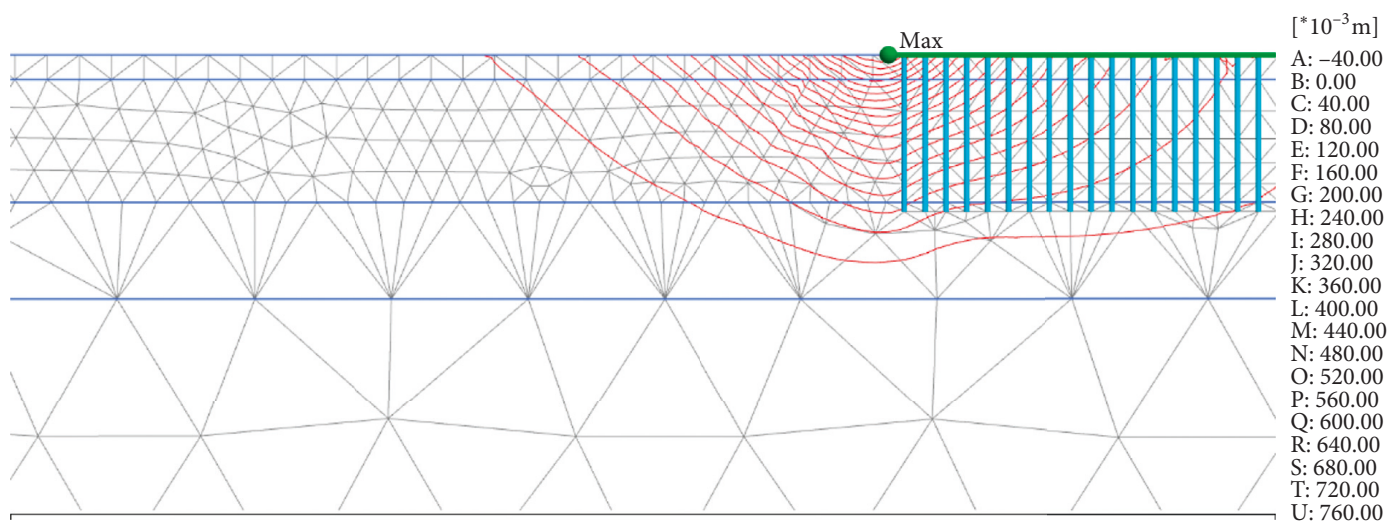

Figure 14: Lateral displacement of the soil outside Section 1.

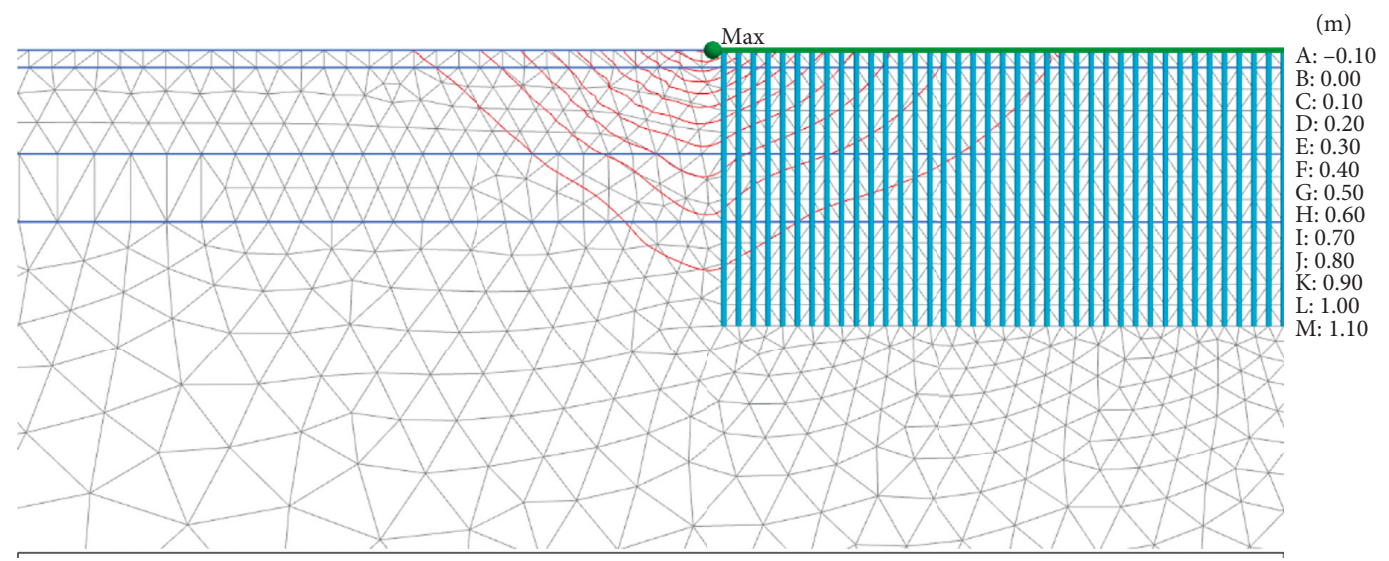

FiguRE 15: Lateral displacement of the soil outside Section 2.

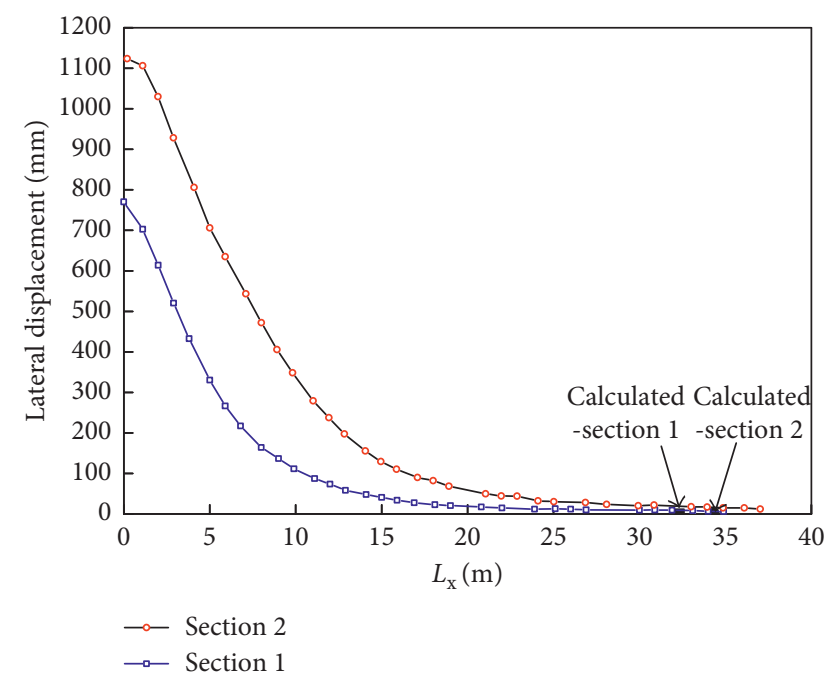

FIGURE 16: Variation of surface lateral displacement in the affected area.

\section{Conclusions}

The performance of vacuum preloading with PVDs was used to reinforce soft soils at the Oujiang, Wenzhou reclamation project. Based on the in situ measurements and subsequent analyses, an empirical formula is proposed to calculate the influence scope of the vacuum preloading method. At the same time, the field case was simulated by the finite-element method. The safe distance away from the treated area is in agreement with simulated results. According to the work done in this paper, we can get the following conclusions:

(1) When the soft soil foundation is consolidated using the vacuum preloading method, a generalisation formula of lateral deformation is proposed to calculate the lateral deformation of the soil at the affected area provided the soil properties of the affected area are known.

(2) Based on the observed results of the case history, an empirical equation is proposed for calculating the influence scope of the vacuum preloading method.

(3) According to the deformation analysis of the soil at the affected area, the safety distance between the reinforcement area boundary and the surrounding building should be determined to $34.32 \mathrm{~m}$ or more when the soft soil foundation is strengthened through vacuum preloading.

\section{Data Availability}

The authors worked with a reputable foundation treatment company and thus were accessible to the data. In the agreement 
of their collaboration, any kinds of data including testing and records were owned by the company and thus are confidential to anybody else.

\section{Conflicts of Interest}

The authors declare that they have no conflicts of interest.

\section{Acknowledgments}

The presented work was supported by the National Key Research and Development Program of China (Grant no. 2016YFC0800203), Program of the International Science and Technology Cooperation (Grant no. 2015DFA71550), Programs of National Natural Science Foundation of China (Grant nos. 51778500, 51778501, 51622810, 51620105008, and 51478364), Key Research and Development Programs of Zhejiang Province (Grant no. 2018C03038), Natural Science Foundation Programs of Zhejiang Province (Grant nos. LR18E080001 and LY17E080010), and Programs of Science and Technology of Wenzhou (Grant nos. S20150015 and S20150030). These financial supports were gratefully acknowledged.

\section{References}

[1] J. C. Chai, J. P. Carter, and S. Hayashi, "Ground deformation induced by vacuum consolidation," Journal of Geotechnical and Geoenvironmental Engineering, vol. 131, no. 12, pp. 1552-1561, 2005.

[2] J. Wang, J. F. Ni, and Y. Q. Cai, "Combination of vacuum preloading and lime treatment for improvement of dredged fill," Engineering Geology, vol. 227, pp. 149-158, 2017.

[3] C. Y. Ong and J. C. Chai, "Lateral displacement of soft ground under vacuum pressure and surcharge load," Frontiers of Architecture and Civil Engineering in China, vol. 5, no. 2, pp. 239-248, 2011.

[4] G. Mesri and A. Q. Khan, "Ground improvement using vacuum loading together with vertical drains," Journal of Geotechnical and Geoenvironmental Engineering, vol. 138, no. 6, pp. 680-689, 2012.

[5] Z. G. Jiang and Z. A. Yao, "Deformation and consolidation effect of soft soils treated by vacuum preloading method," Geotechnical Engineering Technique, vol. 1, pp. 36-38, 2005.

[6] B. Indraratna, C. Rujikiatkamjorn, J. Ameratunga et al., "Performance and prediction of vacuum combined surcharge consolidation at port of brisbane," Journal of Geotechnical and Geoenvironmental Engineering, vol. 137, no. 11, pp. 10091018, 2011.

[7] J. Wang, Y. Q. Cai, J. J. Ma, and J. Chu, "Improved vacuum preloading method for consolidation of dredged clay-slurry fill," Journal of Geotechnical and Geoenvironmental Engineering, vol. 142, no. 11, article 06016012, 2016.

[8] G. Robinsonretnamony, I. Buddhima, and R. Cholachat, "Final state of soils under vacuum preloading," Canadian Geotechnical Journal, vol. 49, no. 6, pp. 729-739, 2012.

[9] R. L. Kondner, "Hyperbolic stress-strain response: cohesive soils," Journal of the Soil Mechanics \& Foundations Division, vol. 89, no. 1, pp. 115-143, 1963.

[10] S. X. Chen, P. P. Ling, and S. Xiu, "Experimental study on deformation behavior of silty clay under unloading," Rock \& Soil Mechanics, vol. 213, no. 4, pp. 548-566, 2007.
[11] H. G. Poulos and E. H. Davis, Elastic Solutions for Soil and Rock Mechanics, John Wiley \& Sons, New York, NY, USA, 1974.

[12] J. C. Chai, N. Miura, and D. T. Bergado, "Preloading clayey deposit by vacuum pressure with cap-drain: analyses versus performance," Geotextiles and Geomembranes, vol. 26, no. 3, pp. 220-230, 2008.

[13] Q. F. Zhu, C. S. Gao, and S. H. Yang, "Transfer properties of vacuum degree in treatment of super-soft muck foundation," Chinese Journal of Geotechnical Engineering, vol. 9, pp. 1429-1433, 2010.

[14] Y. D. Wu, H. S. Wu, R. P. Luo, and C. C. Zeng, "Analytical solutions for vacuum preloading consolidation considering vacuum degree attenuation and change of permeability coefficient in smear zones," Journal of Hehai University (Natural Soiences), vol. 2, pp. 122-128, 2016.

[15] H. L. Li and W. Li, "Research on influence range of vacuum preloading for horizontal displacement of dredger-filled silt foundation," Port Engineering Technology, vol. 6, pp. 85-91, 2016.

[16] Z. Z. Liu, J. W. Ding, and G. Wang, "Calculation method for vacuum preloading induced settlement considering vacuum degree attenuation," Journal of Southeast University (Natural Science Edition), vol. 46, pp. 191-195, 2016.

[17] D. W. Taylor, Fundamentals of Soil Mechanics, John Wiley \& Sons Inc., New York, NY, USA, 1948. 


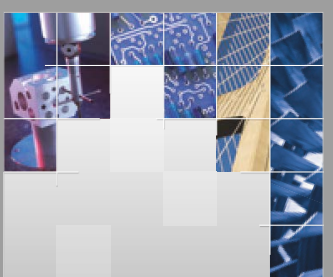

\section{Enfincering}
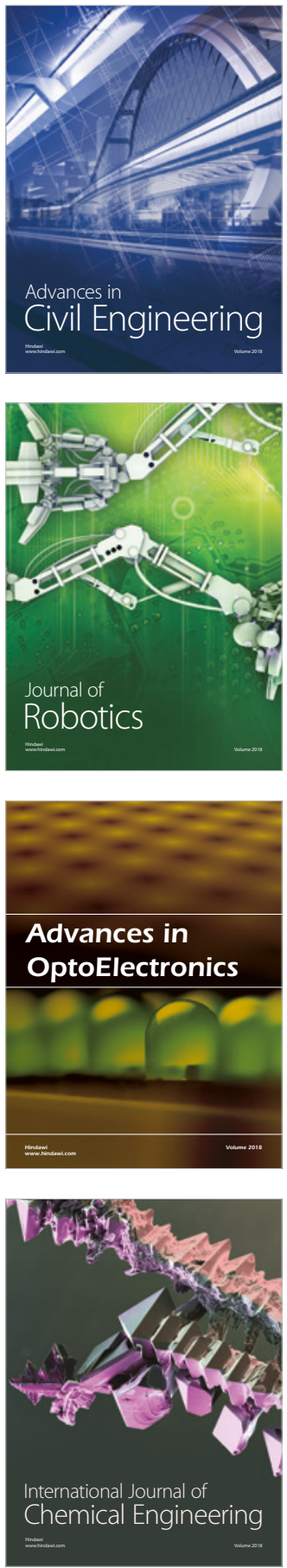

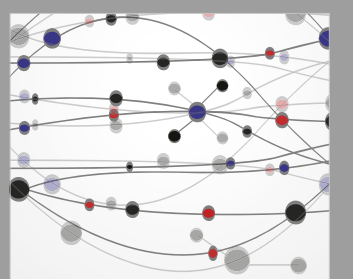

\section{Rotating \\ Machinery}

The Scientific World Journal

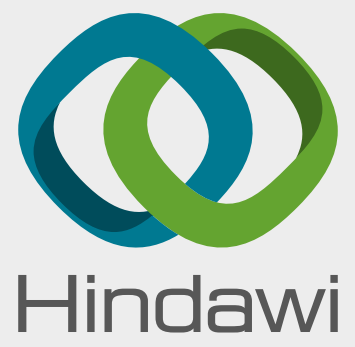

Submit your manuscripts at

www.hindawi.com
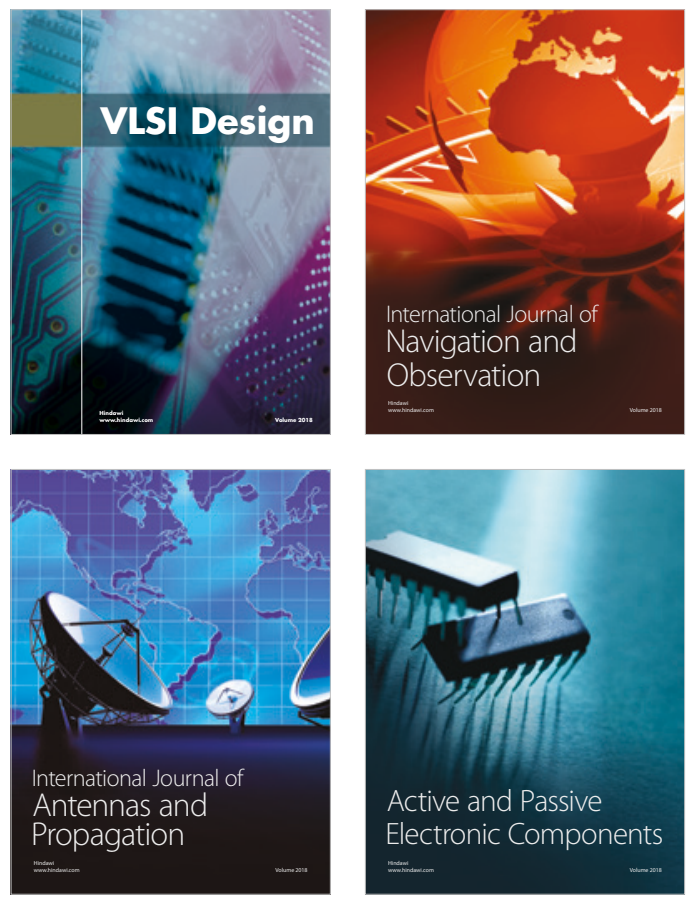
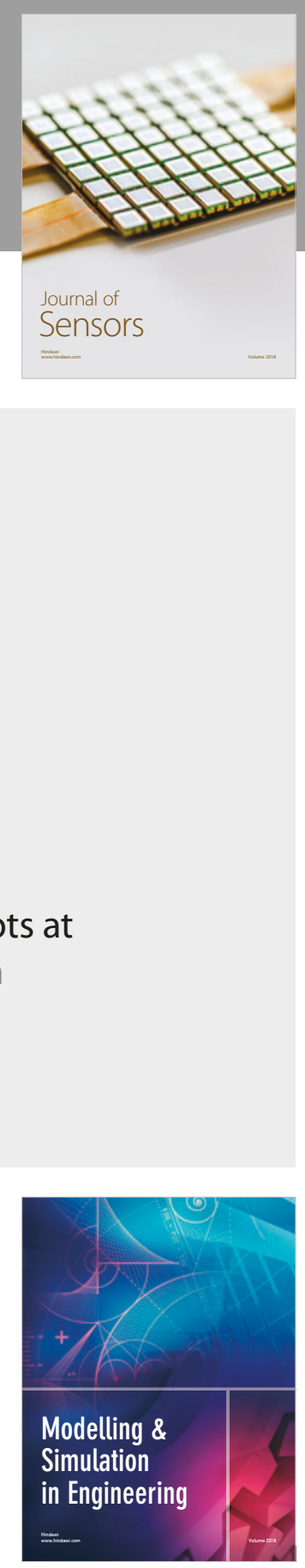

\section{Advances \\ Multimedia}
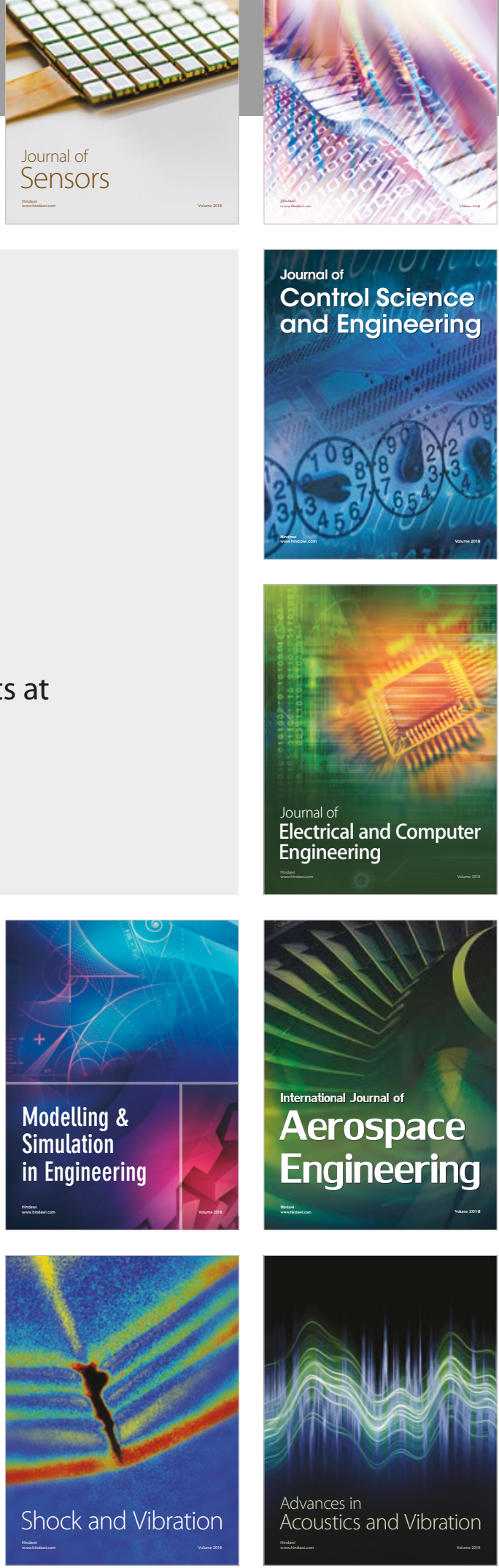